\title{
Design Sliding Mode Controller with Parallel Fuzzy Inference System Compensator to Control of Robot Manipulator
}

\author{
Iman Nazari \\ Research and Development Unit, Electrical and Electronic Researcher, SSP. Co, Shiraz, Iran \\ E-mail:SSP.ROBOTIC@yahoo.com \\ Ali Hosainpour \\ Research and Development Unit, Electrical and Electronic Researcher, SSP. Co, Shiraz, Iran \\ E-mail: SSP.ROBOTIC@yahoo.com
}

Farzin Piltan

Senior Researcher at Research and Development Unit, SanatkadeheSabze Pasargad Company, (S.S.P. Co), Shiraz, Iran E-mail: Piltan_f@iranssp.com

Sara Emamzadeh

Research and Development Unit, Electrical and Electronic Researcher, SSP. Co, Shiraz, Iran E-mail: SSP.ROBOTIC@yahoo.com

Mina Mirzaie

Research and Development Unit, Electrical and Electronic Researcher, SSP. Co, Shiraz, Iran E-mail:SSP.ROBOTIC@yahoo.com

\begin{abstract}
Sliding mode controller (SMC) is a significant nonlinear controller under condition of partly uncertain dynamic parameters of system. This controller is used to control of highly nonlinear systems es pecially for robot manipulators, because this controller is a robust and stable. Conversely, pure sliding mode controller is used in many applications; it has two important drawbacks namely; chattering phenomenon, and nonlinear equivalent dynamic formulation in uncertain dynamic parameter. The nonlinear equivalent dynamic formulation problem and chattering phenomenon in uncertain system can be solved by using artificial intelligence theorem. However fuzzy logic controller is used to control complicated nonlinear dynamic systems, but it cannot guarantee stability and robustness. In this research parallel fuzzy logic theory is used to compensate the systemdynamic uncertainty.
\end{abstract}

Index Terms - Sliding Mode Controller, Robot Manipulator, Chattering Phenomenon, Fuzzy Inference System, Compensator

\section{Introduction}

In modern usage, the word of control has many meanings, this word is usually taken to mean regulate, direct or command. The word feedback plays a vital role in the advance engineering and science. The conceptual frame work in Feed-back theory has developed only since world war II. In the twentieth century, there was a rapid growth in the application of feedback controllers in process industries. According to Ogata, to do the first significant work in three-term or PID controllers which Nicholas Minorsky worked on it by automatic controllers in 1922. In 1934, Stefen Black was invention of the feedback amplifiers to develop the negative feedback amplifier[3]. Negative feedback invited communications engineer Harold Black in 1928 and it occurs when the output is subtracted from the input. Automatic control has played an important role in advance science and engineering and its extreme importance in many industrial applications, i.e., aerospace, mechanical engineering and robotic systems. The first significant work in automatic control was James Watt's centrifugal governor for the speed control in motor engine in eighteenth century[2]. There are several methods for controlling a robot manipulator, which all of them follow two common goals, namely, hardware/software implementation and acceptable 
performance. However, the mechanical design of robot manipulator is very important to select the best controller but in general two types schemes can be presented, namely, a joint space control schemes and an operation space control schemes [1-10]. Joint space and operational space control are closed loop controllers which they have been used to provide robustness and rejection of disturbance effect. The main target in joint space controller is design a feedback controller that allows the actual motion $\left(q_{a}(t)\right)$ tracking of the desired motion $\left(q_{d}(t)\right)$. This control problem is classified into two main groups. Firstly, transformation the desired motion $X_{d}(t)$ to joint variable $q_{d}(t)$ by inverse kine matics of robot manipulators [6]. The main target in operational space controller is to design a feedback controller to allow the actual end-effector motion $X_{a}(t)$ to track the desired endeffector motion $X_{d}(t)$. This control methodology requires a greater algorithmic complexity and the inverse kinematics used in the feedback control loop. Direct measurement of operational space variables are very expensive that caused to limitation used of this controller in industrial robot manipulators [6]. One of the simplest ways to analys is control of multiple DOF robot manipulators are analyzed each joint separately such as SISO systems and design an independent joint controller for each joint. In this methodology, the coupling effects between the joints are modeled as disturbance inputs. To make this controller, the inputs are modeled as: total velocity/displacement and disturbance. Design a controller with the same formulation and different coefficient, low cost hardware and simple structure controller are some of most important independent-joint space controller advantages. Nonlinear controllers divided into six groups, namely, feedback linearization (computed-torque control), passivity-based control, sliding mode control (variable structure control), artificial intelligence control, Lyapunov-based control and adaptive control[11-36].

Sliding mode controller (SMC) is a powerful nonlinear controller which has been analyzed by many researchers especially in recent years. This theory was first proposed in the early 1950 by Emelyanov and several co-workers and has been extensively developed since then with the invention of high speed control devices [2]. The main reason to opt for this controller is its acceptable control performance in wide range and solves two most important challenging topics in control which names, stability and robustness [37-69]. Sliding mode controller is divided into two main sub controllers: discontinues controller $\left(\boldsymbol{\tau}_{\text {dis }}\right)$ and equivalent controller $\left(\boldsymbol{\tau}_{\boldsymbol{e q}}\right)$.Discontinues controller causes an acceptable tracking performance at the expense of very fast switching. Conversely in this theory good trajectory following is based on fast switching, fast switching is caused to have system instability and chattering phenomenon. Fine tuning the sliding surface slope is based on nonlinear equivalent part $[1,6]$. However, this controller is used in many applications but, pure sliding mode controller has two most important challenges: chattering phenomenon and nonlinear equivalent dynamic formulation in uncertain parameters [20]. Chattering phenomenoncan causes some problems such as saturation and heats the mechanical parts of robot manipulators or drivers. To reduce or eliminate the chattering, various papers have been reported by many researchers which classified into two most important methods: boundary layer saturation method and estimated uncertainties method [45-69]. In boundary layer saturation method, the basic idea is the discontinuous method replace ment by saturation (linear) method with small neighborhood of the switching surface. This replacement caused to increase the error performance against with the considerable chattering reduction. As mentioned [44-69]sliding mode fuzzy controller (SMFC) is fuzzy controller based on sliding mode technique to most exceptional stability and robustness. Sliding mode fuzzy controller has the two most important advantages: reduce the number of fuzzy rule base and increase robustness and stability. Conversely sliding mode fuzzy controller has the above advantages, define the sliding surface slope coefficient very carefully is the main disadvantage of this controller. Estimated uncertainty method used in term of uncertainty estimator to compensation of the system uncertainties. It has been used to solve the chattering phenomenon and also nonlinear equivalent dynamic. If estimator has an acceptable performance to compensate the uncertainties, the chattering is reduced. Research on estimated uncertainty to reduce the chattering is significantly growing as their applications such as industrial automation and robot manipulator. For instance, the applications of artificial intelligence, neural networks and fuzzy logic on estimated uncertainty method have been reported in [25-69].

In recent years, artificial intelligence theory has been used in sliding mode control systems. Neural network, fuzzy logic and neuro-fuzzy are synergically combined with nonlinear classical controller and used in nonlinear, time variant and uncertain plant (e.g., robot manipulator). Fuzzy logic controller (FLC) is one of the most important applications of fuzzy logic theory. This controller can be used to control nonlinear, uncertain, and noisy systems. This method is free of some model techniques as in model-based controllers. As mentioned that fuzzy logic application is not only limited to the modelling of nonlinear systems [31-69] but also this method can help engineers to design a model-free controller. Control robot arm manipulators using model-based controllers are based on manipulator dynamic model. These controllers often have many problems for modelling. Conventional controllers require accurate information of dynamic model of robot manipulator, but most of time these models are MIMO, nonlinear and partly uncertain therefore calculate accurate dynamic model is complicated [32]. The main reasons to use fuzzy logic methodology are able to give approximate recommended solution for uncertain and also certain complicated systems to easy understanding and flexible. Fuzzy logic provides a method to design a 
model-free controller for nonlinear plant with a set of IF-THEN rules [32-44].

Based on mechanical and control methodologies research in robotic system, mechanical design, type of actuators and type of systems drive play important roles to have the best performance controller. This section has focused on the robot manipulator mechanical classification. Types of kinematics chain, i.e., serial Vs. parallel manipulators, and types of connection between link and join actuators, i.e., highly geared systems Vs. direct-drive systems are presented in the following sections because these topics played important roles to select and design the best acceptable performance controllers [1- 14]. A serial link robot is a sequence of joints and links which begins with a base frame and ends with an end-effector. This type of robot man ipulators, comparing with the load capacity is more weightily because each link must be supported the weights of all next links and actuators between the present link and end-effector [1- 6]. Serial robot manipulators have been used in automotive industry, medical application, and also in research laboratories [1-6]. In contrast, parallel robot manipulators design according to close loop which base frame is connected to the end-effector frame with two or more kinematic chains [6]. In the other words, a parallel link robot has two or more branches with some joints and lin ks, which support the load in parallel. Parallel robot have been used in many applications such as expensive flight simulator, medical robotics (I.e., high accuracy, high repeatability, high precision robot surgery), and machinery tools [1-10]. Parallel links robot man ipulators have higher accuracy and faster than serial links robot manipulators but the work space limitation in serial links robot manipulator is lower than parallel links robot manipulator. From control point of view, the coupling between different kinematic chains can generate the uncertainty problems which cause difficult controller design of parallel robot manipulator [1- 6]. One of the most important classifications in controlling the robot manipulator is how the links have connected to the actuators. This classification divides into two main groups: highly geared (e.g., 200 to 1) and direct drive (e.g., 1 to 1 ) [1]. High gear ratios reduce the nonlinear coupling dynamic parameters in robot manipulator. In this case, each joint is modeled the same as SISO systems. In high gear robot manipulators which generally are used in industry, the couplings are modeled as a disturbance for SISO systems [14]. Direct drive increases the coupling of nonlinear dynamic parameters of robot manipulators. This effect should be considered in the design of control systems. As a result some control and robotic researchers' works on nonlinear robust controller design [2].

Normal combinations of fuzzy logic methodology (FLM) and sliding mode (SMC) are to apply these two controllers at the same time, while FLM compensates the control error, SMC reduces the remain error of fuzzy inference system such that the final tracking error is asymptotically stable. The chattering is eliminating, because SMC and FLM work parallel. In this paper, the asymptotic stability of SMC control with parallel fuzzy logic compensation is proposed (SMC+FLM). The fuzzy inference system is used to approximate the nonlinear plant. A dead one algorithm is applied for the fuzzy control. After the regulation error enter converges to the dead-zone, a super-twisting second-order slidingmode is used to guarantee finite time convergence of the whole control (FLM+SMC). By means of a Lyapunov approach, we prove that this type of control can ensure finite time convergence and less chattering than SMC.

This paper is organized as follows; second part focuses on the modeling dynamic formulation based on Lagrange methodology, fuzzy logic methodology and sliding mode controller to have a robust control. Third part is focused on the methodology which can be used to reduce the error, increase the performance quality and increase the robustness and stability. Simulation result and discussion is illustrated in forth part which based on trajectory following and disturbance rejection. The last part focuses on the conclusion and compare between this method and the other ones.

\section{Theorem}

\subsection{Dynamic Formulation of IC Engine's Fuel Ratio}

The equation of a multi degrees of freedom (DOF) robot manipulator is calculated by the following equation[6-34]:

$$
M(q) \ddot{q}+N(q, \dot{q})=\tau
$$

Where $\tau$ is $n \times 1$ vector of actuation torque, $M(q)$ is $\mathrm{n} \times \mathrm{n}$ symmetric and positive define inertia matrix, $\mathrm{N}(\mathrm{q}, \dot{\mathrm{q}})$ is the vector of nonlinearity term, and $\mathrm{q}$ is $\mathrm{n} \times 1$ position vector. In equation 2.8 if vector of nonlinearity term derive as Centrifugal, Corio lis and Gravity terms, as a result robot manipulator dynamic equation can also be written as [80]:

$$
\begin{aligned}
& \mathrm{N}(\mathrm{q}, \dot{\mathrm{q}})=\mathrm{V}(\mathrm{q}, \dot{\mathrm{q}})+\mathrm{G}(\mathrm{q}) \\
& \mathrm{V}(\mathrm{q}, \dot{\mathrm{q}})=\mathrm{B}(\mathrm{q})[\dot{\mathrm{q}} \dot{\mathrm{q}}]+\mathrm{C}(\mathrm{q})[\dot{\mathrm{q}}]^{2} \\
& \tau=\mathrm{M}(\mathrm{q}) \ddot{\mathrm{q}}+\mathrm{B}(\mathrm{q})[\dot{\mathrm{q}} \dot{\mathrm{q}}]+\mathrm{C}(\mathrm{q})[\dot{\mathrm{q}}]^{2}+\mathrm{G}(\mathrm{q})
\end{aligned}
$$

Where, $\mathrm{B}(\mathrm{q})$ is matrix of coriolis torques, $\mathrm{C}(\mathrm{q})$ is matrix of centrifugal torque, $[\dot{\mathrm{q}} \dot{\mathrm{q}}]$ is vector of joint velocity that it can give by: $\left[\dot{\mathrm{q}}_{1} \cdot \dot{\mathrm{q}}_{2}, \dot{\mathrm{q}}_{1} \cdot \dot{\mathrm{q}}_{3}, \ldots . \dot{\mathrm{q}}_{1} \cdot \dot{\mathrm{q}}_{\mathrm{n}}, \dot{\mathrm{q}}_{2} \cdot \dot{\mathrm{q}}_{3}, \ldots . .\right]^{\mathrm{T}}$, and $[\dot{\mathrm{q}}]^{2}$ is vector, that it can given by: $\left[\dot{q}_{1}{ }^{2}, \dot{\mathrm{q}}_{2}{ }^{2}, \dot{\mathrm{q}}_{3}{ }^{2}, \ldots .\right]^{\mathrm{T}}$.

In robot manipulator dynamic part the inputs are torques and the outputs are actual displacements, as a result in (4) it can be written as [1-39]; 


$$
\ddot{\mathrm{q}}=\mathrm{M}^{-1}(\mathrm{q}) .\{\tau-\mathrm{N}(\mathrm{q}, \dot{\mathrm{q}})\}
$$

To implementation (5) the first step is implement the kinetic energy matrix (M) parameters by used of Lagrange's formulation. The second step is implementing the Coriolis and Centrifugal matrix which they can calculate by partial derivatives of kinetic energy. The last step to implement the dynamic equation of robot manipulator is to find the gravity vector by performing the summation of Lagrange's formulation.

The kinetic energy equation $(M)$ is a $n \times n$ symmetric matrix that can be calculated by the following equation;

$$
\begin{aligned}
& \boldsymbol{M}(\theta)=m_{1} J_{v 1}^{T} J_{v 1}+J_{\omega 1}^{T C 1} I_{1} J_{\omega 1}+m_{2} J_{v 2}^{T} J_{v 2}+ \\
& J_{\omega 2}^{T C 2} I_{2} J_{\omega 2}+m_{3} J_{v 3}^{T} J_{v 3}+J_{\omega 3}^{T C 3} I_{3} J_{\omega 3}+ \\
& m_{4} J_{v 4}^{T} J_{v 4}+J_{\omega 4}^{T C 4} I_{4} J_{\omega 4}+m_{5} J_{v 5}^{T} J_{v 5}+ \\
& J_{\omega 5}^{T C 5} I_{5} J_{\omega 5}+m_{6} J_{v 6}^{T} J_{v 6}+J_{\omega 6}^{T C 6} I_{6} J_{\omega 6}
\end{aligned}
$$

As mentioned above the kinetic energy matrix in $n$ DOF is a $n \times n$ matrix that can be calculated by the following matrix $[1,6]$

$$
\mathrm{M}(\mathrm{q})=\left[\begin{array}{cccccc}
\mathrm{M}_{11} & \mathrm{M}_{12} & \ldots & \ldots & \ldots . . & \mathrm{M}_{1 \mathrm{n}} \\
\mathrm{M}_{21} & \ldots & \ldots & \ldots & \ldots . & \mathrm{M}_{2 \mathrm{n}} \\
\ldots & \ldots & \ldots & \ldots & \ldots & \ldots \\
\ldots & \ldots & \ldots & \ldots & \ldots & \ldots \\
\ldots & \ldots & \ldots & \ldots & \ldots & \ldots \\
\mathrm{M}_{\mathrm{n} .1} & \ldots & \ldots & \ldots & \ldots & \mathrm{M}_{\text {n.n }}
\end{array}\right]
$$

The Coriolis matrix (B) is a $\mathrm{n} \times \frac{\mathrm{n}(\mathrm{n}-1)}{2}$ matrix which calculated as follows;

$$
\begin{aligned}
& \mathrm{B}(\mathrm{q}) \\
& =\left[\begin{array}{cccccccccc}
\mathrm{b}_{112} & \mathrm{~b}_{113} & \ldots & \mathrm{b}_{11 \mathrm{n}} & \mathrm{b}_{123} & \ldots & \mathrm{b}_{12 n} & \ldots & \ldots & \mathrm{b}_{1 . n-1 . n} \\
\mathrm{~b}_{212} & \ldots & \ldots & \mathrm{b}_{21 \mathrm{n}} & \mathrm{b}_{223} & \ldots & \ldots & \ldots & \ldots & \mathrm{b}_{2 . \mathrm{n}-1 . \mathrm{n}} \\
\ldots & \ldots & \ldots & \ldots & \ldots & \ldots & \ldots & \ldots & \ldots & \ldots \\
\ldots & \ldots & \ldots & \ldots & \ldots & \ldots & \ldots & \ldots & \ldots & \ldots \\
\ldots & \ldots & \ldots & \ldots & \ldots & \ldots & \ldots & \ldots & \ldots & \ldots \\
b_{\text {n.1.2 }} & \ldots & \ldots & \mathrm{b}_{\text {n.1.n }} & \ldots & \ldots & \ldots & \ldots & \ldots & \mathrm{b}_{\text {n.n-1.n }}
\end{array}\right]
\end{aligned}
$$

and the Centrifugal matrix $(\mathrm{C})$ is a $\mathrm{n} \times \mathrm{n}$ matrix;

$$
C(q)=\left[\begin{array}{ccc}
C_{11} & \cdots & C_{1 n} \\
\vdots & \ddots & \vdots \\
C_{n 1} & \cdots & C_{n n}
\end{array}\right]
$$

And last the Gravity vector $(\mathrm{G})$ is a $\mathrm{n} \times 1$ vector;

$$
G(q)=\left[\begin{array}{c}
g_{1} \\
g_{2} \\
\vdots \\
g_{n}
\end{array}\right]
$$

\subsection{Sliding Mode Controller}

Design a robust controller for robot manipulator is essential because robot manipulator has highly nonlinear dynamic parameters. In this section formulations of sliding mode controller for robot manipulator is presented based on $[1,6]$. Consider a nonlinear single input dynamic systemis defined by [6]:

$$
x^{(n)}=f(\vec{x})+b(\vec{x}) u
$$

Where $u$ is the vector of control input, $\mathbf{x}^{(\mathbf{n})}$ is the $\mathbf{n}^{\text {th }}$ derivation of $\mathbf{x}, \mathbf{x}=\left[\mathbf{x}, \dot{\mathbf{x}}, \ddot{\mathbf{x}}, \ldots, \mathbf{x}^{(\mathbf{n}-\mathbf{1})}\right]^{\mathbf{T}}$ is the state vector, $\mathbf{f}(\mathbf{x})$ is unknown or uncertainty, and $\mathbf{b}(\mathbf{x})$ is of known sign function. The main goal to design this controller is train to the desired state; $\mathbf{x}_{\mathbf{d}}=$ $\left[\mathbf{x}_{\mathbf{d}}, \dot{\mathbf{x}}_{\mathbf{d}}, \ddot{\mathbf{x}}_{\mathbf{d}}, \ldots, \mathbf{x}_{\mathbf{d}}{ }^{(\mathbf{n}-1)}\right]^{\mathbf{T}}$, and trucking error vector is defined by [6]:

$$
\tilde{x}=x-x_{d}=\left[\tilde{x}, \ldots, \tilde{x}^{(n-1)}\right]^{T}
$$

A time-varying sliding surface $\mathbf{s}(\mathbf{x}, \mathbf{t})$ in the state space $\mathbf{R}^{\mathbf{n}}$ is given by [6]:

$$
s(x, t)=\left(\frac{d}{d t}+\lambda\right)^{n-1} \tilde{x}=0
$$

where $\lambda$ is the positive constant. To further penalize tracking error, integral part can be used in sliding surface part as follows [6]:

$$
s(x, t)=\left(\frac{d}{d t}+\lambda\right)^{n-1}\left(\int_{0}^{t} \tilde{x} d t\right)=0
$$

The main target in this methodology is kept the sliding surface slope $\mathbf{s}(\mathbf{x}, \mathbf{t})$ near to the zero. Therefore, one of the common strategies is to find input $\mathbf{U}$ outside of $\mathbf{s}(\mathbf{x}, \mathbf{t})[6]$.

$$
\frac{1}{2} \frac{d}{d t} s^{2}(x, t) \leq-\zeta|s(x, t)|
$$

where $\zeta$ is positive constant.

$$
\text { If } S(0)>0 \rightarrow \frac{d}{d t} S(t) \leq-\zeta
$$

To eliminate the derivative term, it is used an integral term from $\mathrm{t}=0$ to $\mathrm{t}=\mathbf{t}_{\text {reach }}$

$$
\begin{aligned}
\int_{t=0}^{\mathrm{t}=\mathrm{t}_{\text {reach }} \frac{\mathrm{d}}{\mathrm{dt}} \mathrm{S}(\mathrm{t})} & \leq-\int_{\mathrm{t}=0}^{\mathrm{t}=\mathrm{t}_{\text {reach }}} \eta \rightarrow \mathrm{S}\left(\mathrm{t}_{\text {reach }}\right) \\
& -\mathrm{S}(0) \leq-\zeta\left(\mathrm{t}_{\text {reach }}-0\right)
\end{aligned}
$$

Where $t_{\text {reach }}$ is the time that trajectories reach to the sliding surface so, suppose $\mathrm{S}\left(\mathrm{t}_{\text {reach }}=0\right)$ defined as 


$$
0-\mathrm{s}(0) \leq-\eta\left(\mathrm{t}_{\text {reach }}\right) \rightarrow \mathrm{t}_{\text {reach }} \leq \frac{\mathrm{S}(0)}{\zeta}
$$

And

$$
\begin{aligned}
& \text { if } \mathrm{S}(0)<0 \rightarrow 0-\mathrm{S}(0) \leq-\eta\left(\mathrm{t}_{\text {reach }}\right) \rightarrow \\
& \mathrm{s}(0) \leq-\zeta\left(\mathrm{t}_{\text {reach }}\right) \rightarrow \mathrm{t}_{\text {reach }} \leq \frac{|\mathrm{s}(0)|}{\eta}
\end{aligned}
$$

Equation (19) guarantees time to reach the sliding surface is smaller than $\frac{|\mathrm{S}(0)|}{\zeta}$ since the trajectories are outside of $\mathrm{S}(\mathrm{t})$.

$$
\text { if } S_{t_{\text {reach }}}=S(0) \rightarrow \operatorname{error}\left(x-x_{d}\right)=0
$$

suppose $\mathrm{S}$ is defined as

$$
\begin{aligned}
& s(x, t)=\left(\frac{d}{d t}+\lambda\right) \quad \tilde{x}=\left(\dot{x}-\dot{x}_{d}\right)+ \\
& \lambda\left(x-x_{d}\right)
\end{aligned}
$$

The derivation of $\mathrm{S}$, namely, $\dot{\mathrm{S}}$ can be calculated as the following;

$$
\dot{S}=\left(\ddot{x}-\ddot{x}_{d}\right)+\lambda\left(\dot{x}-\dot{x}_{d}\right)
$$

suppose the second ordersystemis defined as;

$$
\ddot{\mathrm{x}}=\mathrm{f}+\mathrm{u} \rightarrow \dot{\mathrm{S}}=\mathrm{f}+\mathrm{U}-\ddot{\mathrm{x}}_{\mathrm{d}}+\lambda\left(\dot{\mathrm{x}}-\dot{\mathrm{x}}_{\mathrm{d}}\right)
$$

Where $\mathrm{f}$ is the dynamic uncertain, and also since $\mathrm{S}=0$ and $\dot{\mathrm{S}}=0$, to have the best approximation , $\widehat{U}$ is defined as

$$
\widehat{U}=-\hat{f}+\ddot{x}_{d}-\lambda\left(\dot{x}-\dot{x}_{d}\right)
$$

A simple solution to get the sliding condition when the dynamic parameters have uncertainty is the switching control law:

$$
\mathrm{U}_{\mathrm{dis}}=\widehat{\mathrm{U}}-\mathrm{K}(\overrightarrow{\mathrm{x}}, \mathrm{t}) \cdot \operatorname{sgn}(\mathrm{s})
$$

where the switching function sgn $(S)$ is defined as $[1,6]$

$$
\operatorname{sgn}(s)= \begin{cases}1 & s>0 \\ -1 & s<0 \\ 0 & s=0\end{cases}
$$

and the $K(\vec{x}, t)$ is the positive constant. Suppose by (15) the following equation can be written as,

$$
\begin{aligned}
\frac{1}{2} \frac{\mathrm{d}}{\mathrm{dt}} \mathrm{s}^{2}(\mathrm{x}, \mathrm{t})=\dot{\mathrm{S}} \cdot \mathrm{S} & =[\mathrm{f}-\hat{\mathrm{f}}-\operatorname{Ksgn}(\mathrm{s})] \cdot \mathrm{S} \\
= & (\mathrm{f}-\hat{\mathrm{f}}) \cdot \mathrm{S}-\mathrm{K}|\mathrm{S}|
\end{aligned}
$$

and if the equation (19) instead of (18) the sliding surface can be calculated as

$$
\begin{aligned}
& s(x, t)=\left(\frac{d}{d t}+\lambda\right)^{2}\left(\int_{0}^{t} \tilde{x} d t\right)=\left(\dot{x}-\dot{x}_{d}\right)+ \\
& 2 \lambda\left(\dot{x}-\dot{x}_{d}\right)-\lambda^{2}\left(x-x_{d}\right)
\end{aligned}
$$

in this method the approximation of $U$ is computed as [10-27]

$$
\widehat{U}=-\hat{\mathrm{f}}+\ddot{\mathrm{x}}_{\mathrm{d}}-2 \lambda\left(\dot{\mathrm{x}}-\dot{\mathrm{x}}_{\mathrm{d}}\right)+\lambda^{2}\left(\mathrm{x}-\mathrm{x}_{\mathrm{d}}\right)
$$

Based on above discussion, the sliding mode control law for a multi degrees of freedom robot manipulator is written as [11-53]:

$$
\tau=\tau_{\mathrm{eq}}+\tau_{\mathrm{dis}}
$$

where, the model-based component $\boldsymbol{\tau}_{\mathbf{e q}}$ is the nominal dynamics of systems and $\boldsymbol{\tau}_{\mathbf{e q}}$ for first $3 \mathrm{DOF}$ PUMA robot manipulator can be calculate as follows [1]:

$$
\tau_{\text {eq }}=\left[M^{-1}(B+C+G)+\dot{S}\right] M
$$

and $\boldsymbol{\tau}_{\mathbf{d} \text { is }}$ is computed as [1];

$$
\tau_{\text {dis }}=\mathrm{K} \cdot \operatorname{sgn}(\mathrm{S})
$$

by replace the formulation (29) in (30) the control output can be written as;

$$
\tau=\tau_{\mathrm{eq}}+\mathrm{K} . \operatorname{sgn}(\mathrm{S})
$$

Figure 1 shows the position classical sliding mode control for PUMA 560 robot manipulator. By (33) and (31) the sliding mode control of PUMA 560 robot manipulator is calculated as;

$$
\tau=\left[M^{-1}(B+C+G)+\dot{S}\right] M+K \cdot \operatorname{sgn}(S)
$$

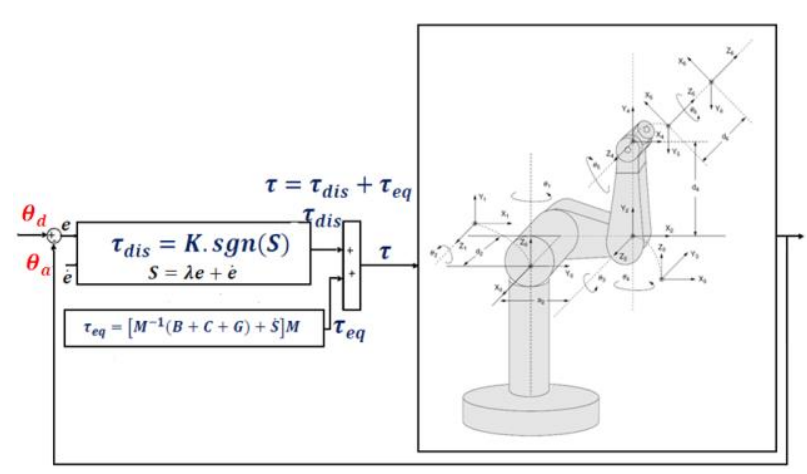

Fig. 1: Block diagram of pure sliding mode controller with switching function 


\subsection{Fuzzy Logic Technique}

Based on foundation of fuzzy logic methodology; fuzzy logic management has played important rule to design nonlinear management for nonlinear and uncertain systems [16]. However the application area for fuzzy control is really wide, the basic form for all command types of controllers consists of;

\section{Input fuzzification (binary-to-fuzzy $[\mathrm{B} / \mathrm{F}]$ conversion)}

Fuzzy rule base (knowledge base), Inference engine and Output defuzzification (fuzzy-to-binary [F/B] conversion). Figure 2 shows the fuzzy controller part. The fuzzy inference engine offers a mechanism for transferring the rule base in fuzzy set which it is divided into two most important methods, namely, Mamdani method and Sugeno method. Mamdani method is one of the common fuzzy inference systems and he designed one of the first fuzzy managements to control of system engine. Mamdani's fuzzy inference system is divided into four major steps: fuzzification, rule evaluation, aggregation of the rule outputs and defuzzification. Michio Sugeno uses a singleton as a membership function of the rule consequent part. The following definition shows the Mamdani and Sugeno fuzzy rule base [22-33]

\section{if $x$ is $A$ and $y$ is $B$ then $z$ is $C$ 'mamdani' if $x$ is $A$ and $y$ is B then $z$ is $f(x, y)$ 'sugeno'}

When $x$ and $y$ have crisp values fuzzification calculates the membership degrees for antecedent part. Rule evaluation focuses on fuzzy operation $(A N D / O R)$ in the antecedent of the fuzzy rules. The aggregation is used to calculate the output fuzzy set and several methodologies can be used in fuzzy logic controller aggregation, namely, Max-Min aggregation, Sum-Min aggregation, Max-bounded product, Max-drastic product, Max-bounded sum, Max-algebraic sum and Min-max. Defuzzification is the last step in the fuzzy inference system which it is used to transform fuzzy set to crisp set. Consequently defuzzification's input is the aggregate output and the defuzzification's output is a crisp number. Centre of gravity method ( $C O G)$ and Centre of area method $(C O A)$ are two most common defuzzification methods.

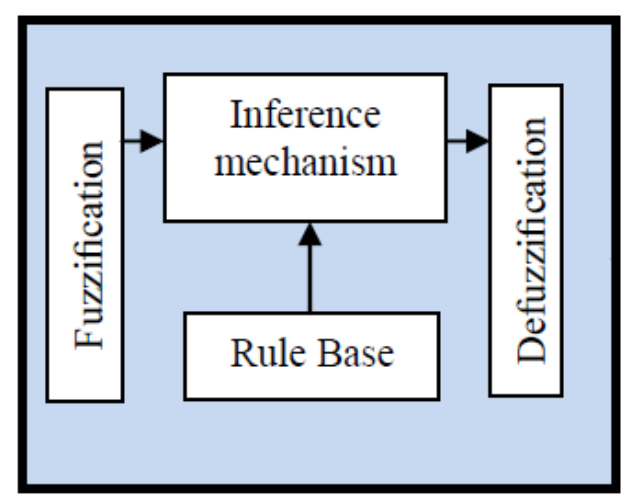

Fig. 2: Fuzzy Controller Part

\section{Methodol ogy:}

Sliding mode controller (SMC) is an important nonlinear controller in a partly uncertain dynamic system's parameters. This controller is used in several applications such as in robotics, process control, aerospace and power electronics. Sliding mode controller is used to control of nonlinear dynamic systems particularly for robot manipulators, because it has a suitable control performance and it is a robust and stable. Conversely pure sliding mode controller is a high-quality nonlinear controller; it has two important problems; chattering phenomenon and nonlinear equivalent dynamic formulation in uncertain dynamic parameter. To reduce the chattering phenomenon and equivalent dynamic problems, this research is focused on applied parallel fuzzy logic theorem in sliding mode controller as a compensator. Fuzzy logic theory is used in parallel with sliding mode controller to compensate the limited uncertainty in system's dynamic. In this method fuzzy logic theorem is applied to sliding mode controller to remove the nonlinear uncertainty part which it is based on nonlinear dynamic formulation. To achieve this goal, the dynamic equivalent part of pure sliding mode controller is modeled by Mamdani's performance/ error-based fuzzy logic methodology. Another researcher's method is based on applied fuzzy logic theorem in sliding mode controller to design a fuzzy model-based controller. This technique was employed to obtain the desired control behavior with a number of information about dynamic model of system and a fuzzy switching control was applied to rein force system performance. Reduce or eliminate the chattering phenomenon and reduce the error are played important role, therefore switching method is used beside the artificial intelligence part to solve the chattering problem with respect to reduce the error. Equivalent part of sliding mode controller is based on nonlinear dynamic formulations of robot manipulator. Robot manipulator's dynamic formulations are highly nonlinear and some of parameters are unknown therefore design a controller based on dynamic formulation is complicated. To solve this challenge parallel fuzzy logic methodology is applied to sliding mode controller. In this method fuzzy logic method is used to compensate some dynamic formulation that they are used in equivalent part. To solve the challenge of sliding mode controller based on nonlinear dynamic formulation this research is focused on compensate the nonlinear equivalent formulation by parallel fuzzy logic controller. In this method; dynamic nonlinear equivalent part is modelled by performance/error-based fuzzy logic controller. In this method; error based Mamdani's fuzzy inference system has considered with two inputs, one output and totally 49 rules. For both sliding mode controller and parallel fuzzy inference system plus sliding mode controller applications the system performance is sensitive to the sliding surface slope coefficient $(\lambda)$. For instance, if large value of $\lambda$ is chosen the response is very fast the system is unstable and conversely, if small value of $\lambda$ is considered the 
response of system is very slow but system is stable. Therefore to have a good response, compute the best value sliding surface slope coefficient is very important. In parallel fuzzy inference system compensator of sliding mode controller the PD-sliding surface is defined as follows:

$$
S=\dot{e}+\lambda_{1} e
$$

where $\lambda_{1}=\operatorname{diag}\left[\lambda_{11}, \lambda_{12}, \lambda_{13}\right]$. The time derivative of $\mathrm{S}$ is computed;

$$
\dot{S}=\ddot{q}_{d}+\lambda_{1} \dot{e}
$$

The parallel fuzzy error-based compensator of slid ing mode controller's output is written;

$$
\hat{\boldsymbol{\tau}}=\tau_{e q_{f u z z y}}+\tau_{S M C}
$$

Based on fuzzy logic methodology

$$
f(x)=U_{f u z z y}=\sum_{l=1}^{M} \theta^{T} \zeta(x)
$$

where $\boldsymbol{\theta}^{\boldsymbol{T}}$ is adjustable parameter (gain updating factor) and $\boldsymbol{\zeta}(\boldsymbol{x})$ is defined by;

$$
\zeta(x)=\frac{\sum_{i} \mu\left(x_{i}\right) x_{i}}{\sum_{i} \mu\left(x_{i}\right)}
$$

Where $\boldsymbol{\mu}\left(\boldsymbol{x}_{\boldsymbol{i}}\right)$ is membership function. $\boldsymbol{\tau}_{\boldsymbol{f u z z} \boldsymbol{y}}$ defined as follows;

$$
\tau_{f u z z y}=\sum_{l=1}^{M} \theta^{T} \zeta(x)=[(B+C+G)]
$$

Design an error-based parallel fuzzycompensate of equivalent part based on Mamdani's fuzzy inference method has four steps, namely, fuzzification, fu zzy ru le base and rule evaluation, aggregation of the rule output (fuzzy inference system) and defuzzification.

Fuzzification: the first step in fuzzification is determine inputs and outputs which, it has two inputs $(e, \dot{e})$ and one output $\left(\tau_{f u z z y}\right)$. The inputs are error (e) which measures the difference between desired and actual output position, and the change of error $(\dot{e})$ which measures the difference between desired and actual velocity and output is fuzzy equivalent torque. The second step is chosen an appropriate membership function for inputs and output which, to simplicity in implementation because it is a linear function with regard to acceptable performance triangular membership function is selected in this research. The third step is chosen the correct labels for each fuzzy set which, in this research namely as linguistic variable. Based on experience knowledge the linguistic variables for error (e) are; Negative Big (NB), Negative Medium
(NM), Negative Small (NS), Zero (Z), Positive Small (PS), Positive Medium (PM), Positive Big (PB), and based on literature [40] and experience knowledge it is quantized into thirteen levels represented by: $-1,-0.83$, $0.66,-0.5,-0.33,-0.16,0,0.16,0.33,0.5,0.66,0.83,1$ the linguistic variables for change of error $(\dot{e})$ are; Fast Left (FL), Medium Left (ML), Slow Left (SL),Zero (Z), Slow Right (SR), Mediu m Right (MR), Fast Right (FR), and it is quantized in to thirteen levels represented by: $6,-5,-0.4,-3,-2,-1,0,1,2,3,4,5,6$, and the linguistic variables to find the output are; Large Left (LL), Medium Left (ML), Small Left (SL), Zero (Z), Small Right (SR), Medium Right (MR), Large Right (LR) and it is quantized in to thirteen levels represented by: -85 , $70.8,-56.7,-42.5,-28.3,-14.2,0,14.2,28.3,42.5,56.7$, $70.8,85$.

Fuzzy rule base and rule evaluation: the first step in rule base and evaluation is to provide a least structured method to derive the fuzzy rule base which, expert experience and control engineering knowledge is used because this method is the least structure of the other one and the researcher derivation the fuzzy rule base from the knowledge of system operate and/or the classical controller. Design the rule base of fuzzy inference system can play important role to design the best performance of parallel fuzzy plus sliding mode controller, that to calculate the fuzzy rule base the researcher is used to heuristic method which, it is based on the behavior of the control of robot manipulator. The complete rule base for this controller is shown in Table 1. Rule evaluation focuses on operation in the antecedent of the fuzzy rules in fuzzy sliding mode controller. This part is used $A N D / O R$ fuzzy operation in antecedent part which $A N D$ operation is used.

Table 1: Modified Fuzzy rule base table

Decrease the overshoot
\begin{tabular}{|c|c|c|c|c|c|c|c|}
\hline$\dot{e} e$ & FL & ML & SL & Z & SR & MR & FR \\
\hline NB & LL & LL & LL & ML & SL & SL & Z \\
\hline NM & LL & ML & ML & ML & SL & Z & SR \\
\hline NS & LL & ML & SL & SL & Z & SR & MR \\
\hline \hline Z & LL & ML & SL & Z & SR & MR & LR \\
\hline PS & ML & SL & Z & SR & SR & MR & LR \\
\hline PM & SL & Z & SR & MR & MR & MR & LR \\
\hline PB & Z & SR & SR & MR & LR & LR & LR \\
\hline
\end{tabular}

Aggregation of the rule output (Fuzzy inference): based onfuzzy methodology, Max-Min aggregation is used in this work (see table 1).

Defuzzification: The last step to design fuzzy inference in our parallel fuzzy compensator plus sliding mode controller is defuzzification. This part is used to transform fuzzy set to crisp set, therefore the input for 
defuzzification is the aggregate output and the output of it is a crisp number. Based on fuzzy methodology Center of gravity method $(C O G)$ is used in this research. Table 2 shows the lookup table in parallel fuzzy compensator sliding mode controller which is computed by COG defuzzification method. Table 2 has 169 cells to shows the error-based fuzzy compensate of equivalent part behavior (see table 2).

Table 2: $\tau_{f u z z y}$ performance: lookup table in parallel fuzzy compensate of sliding mode controller by COG

\begin{tabular}{|c|c|c|c|c|c|c|c|c|c|c|c|c|c|}
\hline $\overrightarrow{\dot{e}}$ & \multicolumn{13}{|c|}{ Membership Function ( $\left.\tau_{\text {fuzzy }}\right)$} \\
\hline$e$ & -6 & -5 & -4 & -3 & -2 & -1 & 0 & 1 & 2 & 3 & 4 & 5 & 6 \\
\hline-1 & -85 & -84.8 & -84.8 & -84 & -82.1 & -81 & -79 & -71 & -68 & -65 & -62 & -60 & -54 \\
\hline-0.83 & -84.8 & -84 & -82 & -80 & $\begin{array}{l}-78 \\
\end{array}$ & -77 & -74 & -70 & -64 & -60 & -56 & -54 & -47 \\
\hline-0.66 & -78 & -73 & -70 & -68 & -64 & -61 & -60 & -57 & -55 & -50 & -47 & -40 & -38 \\
\hline-0.5 & -70 & -60 & -58 & -51 & -42 & -38 & -34 & -33 & -31 & -29 & -28.4 & -28.1 & -28 \\
\hline-0.33 & -50 & -48 & -45 & -40 & -38 & -34 & -32 & -30 & -28 & -26 & -25 & -21 & -20 \\
\hline-0.16 & -30 & -25 & -21 & -18 & -16 & -14 & -10 & -9 & -8 & -7 & -6.8 & -6 & -5 \\
\hline 0 & -10 & -8 & -6 & -1 & 2 & 3 & 6 & 7 & 8 & 10 & 12 & 15 & 17 \\
\hline 0.16 & 15 & 18 & 21 & 22 & 23 & 25 & 27 & 28 & 29 & 30 & 30.5 & 30.8 & 31 \\
\hline 0.33 & 29 & 29.8 & 31 & 33 & 34 & 34.6 & 35 & 35.2 & 36 & 37 & 38 & 39 & 42 \\
\hline 0.5 & 40 & 41 & 42 & 43 & 45 & 45 & 46 & 46.3 & 46.8 & 47 & 48 & 51 & 52 \\
\hline 0.66 & 48 & 49 & 50 & 52 & 53 & 55 & 56 & 57 & 58 & 59 & 60 & 61 & 63 \\
\hline 0.83 & 60 & 61 & 62 & 63 & 64 & 66 & 67 & 68 & 68.5 & 69 & 70 & 70.8 & 71 \\
\hline 1 & 66 & 68.7 & 68.9 & 70 & 72 & 74 & 75 & 77 & 78 & 79 & 81 & 83 & 84 \\
\hline
\end{tabular}

\section{Results}

In this section, we use a benchmark model, robot manipulator, to evaluate our control algorithms. We compare the following managements: classical PD controller, PD fuzzy controller and parallel fuzzy inference compensator plus sliding mode controller which is proposed in this paper. The simulation was implemented in MATLAB/SIMULINK environment.

Close loop res ponse of robot manipulator trajectory planning: Figure 3 illustrates the tracking performance in three types of controllers.
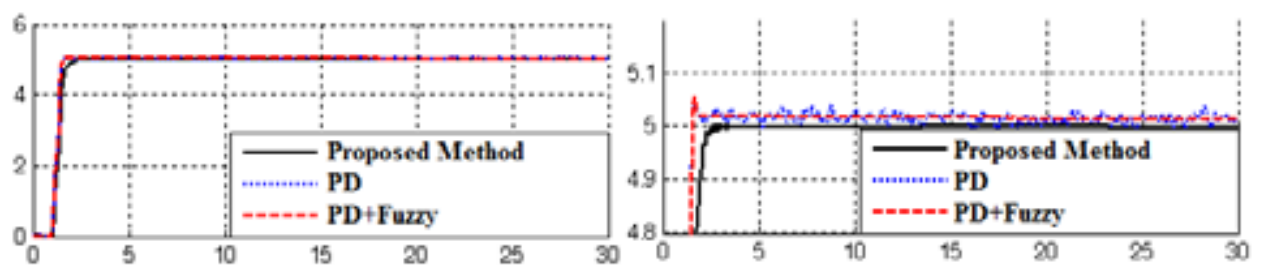

Fig. 3: Linear PD, PD+FLC and Proposed method trajectory following without disturbance

Based on Figure 3; pure PD controller has oscillation in all links, because robot is a highly nonlinear system and control of this system by linear method is very difficult. Based on above graph, however PD+FUZZY controller is a nonlinear methodology but it has difficulty to control this plant because it is a model free controller.
Close loop response of trajectory planning in presence of disturbance: Figure 4 demonstrates the power disturbance elimination in three types of controller in presence of disturbance for robot. The disturbance rejection is used to test the robustness comparisons of these three methodologies.
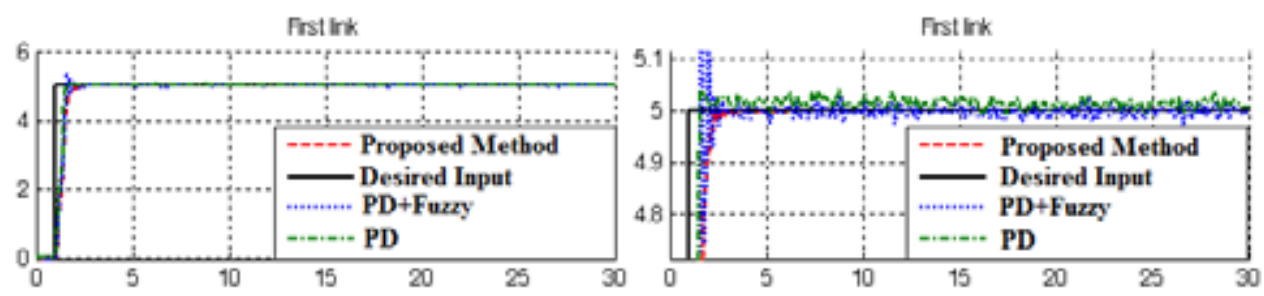

Fig. 4: Linear PD, PD+FLC and Proposed method trajectory following with disturbance 
Based on Figure 4; by comparison with the PD and PD+FLC, proposed methodology is more stable and robust and our method doesn't have any chattering and oscillation.

\section{Conclusion}

The main contributions of this paper are compensating the nonlinear model base controller by nonlinear artificial intelligence model-free compensator. The structure of sliding mode controller with parallel fuzzy inference compensator is new. We propose parallel structure and chattering free compensator: parallel compensation, and chattering free method. The key technique is dead-zone, such that fuzzy inference compensator and sliding mode control can be switched automatically. The stability analysis of parallel fuzzy compensator plus sliding mode controller is test via Lyapunov methodology. The benefits of the proposed method; the chattering effects of parallel fuzzy inference compensator plus sliding mode controller, the slow convergence of the fuzzy and the chattering problem of sliding mode method are avoided effectively.

\section{Acknowledgment}

The authors would like to thank the anonymous reviewers for their careful reading of this paper and for their helpful comments. This work was supported by the SSP Research and Development Corporation Program of Iran under grant no. 2012-Persian Gulf-3C.

\section{Reference:}

[1] G. Robinson, and J. Davies, "Continuum robots - a state of the art,"Proc. IEEE International Conference on Robotics and Automation, Detroit, MI, 1999, vol. 4, pp. 2849-2854.

[2] I.D. Walker, D. Dawson, T. Flash, F. Grasso, R. Hanlon, B. Hochner, W.M. Kier, C. Pagano,C.D. Rahn, Q. Zhang, "Continuum Robot Arms Inspired by Cephalopods, Proceedings SPIE Conference on Unmanned Ground Vehicle Technology VII, Orlando, FL, pp 303-314, 2005.

[3] K. Suzumori, S. Iikura, and H. Tanaka, "Development of Flexible Microactuator and it's Applications to Robotic Mechanisms", Proceedings IEEE International Conference on Robotics and Automation, Sacramento, California, pp. 1622-1627, 1991.

[4] D. Trivedi, C.D. Rahn, W.M. Kier, and I.D. Walker, "Soft Robotics: Biological Inspiration, State of the Art, and Future Research", Applied Bionics and Biomechanics, 5(2), pp. 99-117, 2008.
[5] W. McMahan, M. Pritts, V. Chitrakaran, D. Dienno, M. Grissom, B. Jones, M. Csencsits, C.D. Rahn, D. Dawson, and I.D. Walker, "Field Trials and Testing of "OCTARM" Continuum Robots", Proc. IEEE International Conference on Robotics and Automation, pp. 2336-2341, 2006.

[6] W. McMahan, I.D. Walker, "Octopus-Inspired Grasp Synergies for Continuum Manipulators", Proc. IEEE International Conference on Robotics and Biomimetics, pp. 945- 950, 2009.

[7] I. Boiko, L. Fridman, A. Pisano and E. Usai, "Analysis of chattering in systems with secondorder sliding modes," IEEE Transactions on Automatic Control, No. 11, vol. 52,pp. 2085-2102, 2007.

[8] J. Wang, A. Rad and P. Chan, "Indirect adaptive fuzzy sliding mode control: Part I: fuzzy switching," Fuzzy Sets and Systems, No. 1, vol. 122,pp. 21-30, 2001.

[9] M. Bazregar, Farzin Piltan, A. Nabaee and M.M. Ebrahimi, "Parallel Soft Computing Control Optimization Algorithm for Uncertainty Dynamic Systems", International Journal of Advanced Science and Technology, 51, 2013.

[10] Farzin Piltan, M.H. Yarmahmoudi, M. Mirzaei, S. Emamzadeh, Z. Hivand, "Design Novel Fuzzy Robust Feedback Linearization Control with Application to Robot Manipulator", International Journal of Intelligent Systems and Applications, 5(5), 2013

[11] Sh. Tayebi Haghighi, S. Soltani, Farzin Piltan, M. kamgari, S. Zare, "Evaluation Performance of IC Engine: Linear Tunable Gain Computed Torque Controller Vs. Sliding Mode Controller", International Journal of Intelligent Systems and Applications, 5(6), 2013.

[12] Farzin Piltan, A. R. Salehi \& Nasri B Sulaiman,"Design Artificial Robust Control of Second Order System Based on Adaptive Fuzzy Gain Scheduling", World Applied Science Journal (WASJ), 13 (5): 1085-1092, 2011.

[13] Farzin Piltan, N. Sulaiman, Atefeh Gavahian, Samira Soltani \& Samaneh Roosta, "Design Mathematical Tunable Gain PID-Like Sliding Mode Fuzzy Controller with Minimum Rule Base", International Journal of Robotic and Automation, 2 (3): 146-156, 2011.

[14] Farzin Piltan , N. Sulaiman, Zahra Tajpaykar, Payman Ferdosali \& Mehdi Rashidi, "Design Artificial Nonlinear Robust Controller Based on CTLC and FSMC with Tunable Gain", International Journal of Robotic and Automation, 2 (3): 205-220, 2011.

[15] Farzin Piltan, Mohammad Mansoorzadeh, Saeed Zare, Fatemeh Shahriarzadeh, Mehdi Akbari, 
"Artificial tune of fuel ratio: Design a novel siso fuzzy backstepping adaptive variable structure control", International Journal of Electrical and Computer Engineering (IJECE), 3 (2): 183-204, 2013.

[16] Farzin Piltan, M. Bazregar, M. Kamgari, M. Akbari, M. Piran, "Adjust the fuel ratio by high impact chattering free sliding methodology with application to automotive engine", International Journal of Hybrid Information Technology (IJHIT), 6 (1): 13-24, 2013.

[17] Shahnaz Tayebi Haghighi, S. Soltani, Farzin Piltan, M. Kamgari, S. Zare, "Evaluation Performance of IC Engine: linear tunable gain computed torque controller Vs. Sliding mode controller", I. J. Intelligent system and application, 6 (6): 78-88, 2013.

[18] Farzin Piltan, N. Sulaiman, Payman Ferdosali \& Iraj Assadi Talooki, "Design Model Free Fuzzy Sliding Mode Control: Applied to Internal Combustion Engine", International Journal of Engineering, 5 (4):302-312, 2011.

[19] Farzin Piltan, N. Sulaiman, A. Jalali \& F. Danesh Narouei, "Design of Model Free Adaptive Fuzzy Computed Torque Controller: Applied to Nonlinear Second Order System", International Journal of Robotics and Automation, 2 (4):245-257, 2011

[20] A. Jalali, Farzin Piltan, M. Keshtgar, M. Jalali, "Colonial Competitive Optimization Sliding Mode Controller with Application to Robot Manipulator", International Journal of Intelligent Systems and Applications, 5(7), 2013.

[21] Farzin Piltan, Amin Jalali, N. Sulaiman, Atefeh Gavahian \& Sobhan Siamak, "Novel Artificial Control of Nonlinear Uncertain System: Design a Novel Modified PSO SISO Lyapunov Based Fuzzy Sliding Mode Algorithm”, International Journal of Robotics and Automation, 2 (5): 298 316, 2011.

[22] Farzin Piltan, N. Sulaiman, Iraj Asadi Talooki \& Payman Ferdosali, "Control of IC Engine: Design a Novel MIMO Fuzzy Backstepping Adaptive Based Fuzzy Estimator Variable Structure Control", International Journal of Robotics and Automation, 2 (5):360-380, 2011.

[23] Farzin Piltan, N. Sulaiman, S.Soltani, M. H. Marhaban \& R. Ramli, "An Adaptive Sliding Surface Slope Adjustment in PD Sliding Mode Fuzzy Control For Robot Manipulator", International Journal of Control and Automation, 4 (3): 65-76, 2011.

[24] Farzin Piltan, N. Sulaiman, Mehdi Rashidi, Zahra Tajpaikar \& Payman Ferdosali, "Design and Implementation of Sliding Mode Algorithm: Applied to Robot Manipulator-A Review",
International Journal of Robotics and Automation, 2 (5):265-282, 2011.

[25] Farzin Piltan, N. Sulaiman , Arash Zargari, Mohammad Keshavarz \& Ali Badri, "Design PIDLike Fuzzy Controller with Minimum Rule Base and Mathematical Proposed On-line Tunable Gain: Applied to Robot Manipulator", International Journal of Artificial Intelligence and Expert System, 2 (4):184-195, 2011.

[26] Farzin Piltan, SH. Tayebi HAGHIGHI, N. Sulaiman, Iman Nazari \& Sobhan Siamak, "Artificial Control of PUMA Robot Manipulator: A-Review of Fuzzy Inference Engine and Application to Classical Controller", International Journal of Robotics and Automation, 2 (5):401-425, 2011.

[27] A. Salehi, Farzin Piltan, M. Mousavi, A. Khajeh, M. R. Rashidian, "Intelligent Robust Feed-forward Fuzzy Feedback Linearization Estimation of PID Control with Application to Continuum Robot", International Journal of Information Engineering and Electronic Business, 5(1), 2013.

[28] Farzin Piltan, N. Sulaiman \& I.AsadiTalooki, "Evolutionary Design on-line Sliding Fuzzy Gain Scheduling Sliding Mode Algorithm: Applied to Internal Combustion Engine", International Journal of Engineering Science and Technology, 3 (10):7301-7308, 2011.

[29] Farzin Piltan, Nasri B Su laiman, Iraj Asadi Talooki \& Payman Ferdosali, ”Designing On-Line Tunable Gain Fuzzy Sliding Mode Controller Using Sliding Mode Fuzzy Algorithm: Applied to Internal Combustion Engine" World Applied Science Journal (W ASJ), 15 (3): 422-428, 2011.

[30] Farzin Piltan, M.J. Rafaati, F. Khazaeni, A. Hosainpour, S. Soltani, “A Design High Impact Lyapunov Fuzzy PD-Plus-Gravity Controller with Application to Rigid Manipulator", International Journal of Information Engineering and Electronic Business, 5(1), 2013.

[31] A. Jalali, Farzin Piltan, A. Gavahian, M. Jalali, M. Adibi, "Model-Free Adaptive Fuzzy Sliding Mode Controller Optimized by Particle Swarm for Robot man ipulator", International Journal of Information Engineering and Electronic Business, 5(1), 2013.

[32] Farzin Piltan, N. Sulaiman, Payman Ferdosali, Mehdi Rashidi \& Zahra Tajpeikar, "Adaptive MIMO Fuzzy Compensate Fuzzy Sliding Mode Algorithm: Applied to Second Order Nonlinear System", International Journal of Engineering, 5 (5): 380-398, 2011.

[33] Farzin Piltan, N. Sulaiman, Hajar Nasiri, Sadeq Allahdadi \& Mohammad A. Bairami, "Novel Robot Manipulator Adaptive Artificial Control: Design a Novel SISO Adaptive Fuzzy Sliding Algorithm Inverse Dynamic Like Method", 
International Journal of Engineering, 5 (5): 399 418, 2011.

[34] Farzin Piltan, N. Sulaiman, Sadeq Allahdadi, Mohammadali Dialame \& Abbas Zare, "Position Control of Robot Manipulator: Design a Novel SISO Adaptive Sliding Mode Fuzzy PD Fuzzy Sliding Mode Control", International Journal of Artificial Intelligence and Expert System, 2 (5):208-228, 2011.

[35] M. M. Ebrahimit Farzin Piltan, M. Bazregar and A.R. Nabaee "Intelligent Robust Fuzzy-Parallel Optimization Control of a Continuum Robot Manipulator", International Journal of Control and Automation, 6(3), 2013.

[36] Farzin Piltan, M.A. Bairami, F. Aghayari, M.R. Rashidian, "Stable Fuzzy PD Control with Parallel Sliding Mode Compensation with Application to Rigid Manipulator", International Journal of Information Technology and Computer Science, 5(7), 2013.

[37] Farzin Piltan, N. Sulaiman, Samaneh Roosta, Atefeh Gavahian \& Samira Soltani, "Evolutionary Design of Backstepping Artificial Sliding Mode Based Position Algorithm: Applied to Robot Manipulator", International Journal of Engineering, 5 (5):419-434, 2011.

[38] Farzin Piltan, N. Sulaiman, A min Jalali, Sobhan Siamak \& Iman Nazari, "Control of Robot Manipulator: Design a Novel Tuning MIMO Fuzzy Backstepping Adaptive Based Fuzzy Estimator Variable Structure Control", International Journal of Control and Automation, 4 (4):91-110, 2011.

[39] Farzin Piltan, N. Sulaiman, Atefeh Gavahian, Samaneh Roosta \& Samira Soltani, "On line Tuning Premise and Consequence FIS: Design Fuzzy Adaptive Fuzzy Sliding Mode Controller Based on Lyaponuv Theory", International Journal of Robotics and Automation, 2 (5):381-400, 2011.

[40] Farzin Piltan, N. Sulaiman, Samira Soltani, Samaneh Roosta \& Atefeh Gavahian, "Artificial Chattering Free on-line Fuzzy Sliding Mode Algorith m for Uncertain System: Applied in Robot Manipulator", International Journal of Engineering, 5 (5):360-379, 2011.

[41] Farzin Piltan, F. ShahryarZadeh ,M. Mansoorzadeh ,M. kamgari, S. Zare, "Robust Fuzzy PD Method with Parallel Computed Fuel Ratio Estimation Applied to Automotive Engine "International Journal of Intelligent Systems and Applications, 5(8), 2013.

[42] Farzin Piltan, Sadeq Allahdadi, Mohammad A.Bairami \& Hajar Nasiri, "Design Auto Adjust Sliding Surface Slope: Applied to Robot Manipulator", International Journal of Robotics and Automation, 3 (1):27-44, 2011.
[43] Farzin Piltan, Mohammadali Dialame, Abbas Zare \& Ali Badri, "Design Novel Lookup Table Changed Auto Tuning FSMC:Applied to Robot Manipulator", International Journal of Engineering, 6 (1):25-41, 2012.

[44] Farzin Piltan, M. Keshavarz, A. Badri \& A. Zargari, "Design Novel Nonlinear Controller Applied to RobotManipulator: Design New Feedback Linearization Fuzzy Controller with Minimum Rule Base Tuning Method", International Journal of Robotics and Automation, 3 (1):1-12, 2012.

[45] Farzin Piltan, Mohammad A.Bairami, Farid Aghayari \& Sadeq Allahdadi, "Design Adaptive Artificial Inverse Dynamic Controller: Design Sliding Mode Fuzzy Adaptive New Inverse Dynamic Fuzzy Controller", International Journal of Robotics and Automation, (1):13-26, 2012.

[46] Farzin Piltan, Sadeq Allahdadi, Mohammad A.Bairami \& Hajar Nasiri, "Design Auto Adjust Sliding Surface Slope: Applied to Robot Manipulator", International Journal of Robotics and Automation, 3 (1):27-44, 2012.

[47] Farzin Piltan, F. Aghayari, M. Rashidian \& M. Shamsodini, "A New Estimate Sliding Mode Fuzzy Controller for RoboticManipulator", International Journal of Robotics and Automation, 3 (1):45-60, 2012

[48] Farzin Piltan, Iman Nazari, Sobhan Siamak, Payman Ferdosali, "Methodology of FPGA-Based Mathematical error-Based Tuning Sliding Mode Controller", International Journal of Control and Automation, 5(1), 89-118, 2012.

[49] Farzin Piltan, Bamdad Boroomand, Arman Jahed \& Hossein Rezaie, "Methodology of Mathematical Error-Based Tuning Sliding Mode Controller", International Journal of Engineering, 6 (2):96-117, 2012.

[50] Farzin Piltan, S. Emamzadeh, Z. Hivand, F. Shahriyari \& Mina Mirazaei. " PUMA-560 Robot Manipulator Position Sliding Mode Control Methods Using MATLAB/SIMULINK and Their Integration into Graduate/Undergraduate Nonlinear Control, Robotics and MATLAB Courses", International Journal of Robotics and Automation, 3(3):106-150, 2012.

[51] Farzin Piltan, A. Hosainpour, E. Mazlomian, M.Shamsodini, M.H Yarmahmoudi. "Online Tuning Chattering Free Sliding Mode Fuzzy Control Design: Lyapunov Approach", International Journal of Robotics and Automation, 3(3):77-105, 2012.

[52] Farzin Piltan, R. Bayat, F. Aghayari, B. Boroomand. "Design Error-Based Linear ModelFree Evaluation Performance Computed Torque 
Controller", International Journal of Robotics and Automation, 3(3):151-166, 2012.

[53] Farzin Piltan, J. Meigolinedjad, S. Mehrara, S. Rahmdel. "Evaluation Performance of $2^{\text {nd }}$ Order Nonlinear System: Baseline Control Tunable Gain Sliding Mode Methodology", International Journal of Robotics and Automation, 3(3): 192-211, 2012.

[54] Farzin Piltan, Mina Mirzaei, Forouzan Shahriari, Iman Nazari, Sara Emamzadeh, "Design Baseline Computed Torque Controller", International Journal of Engineering, 6(3): 129-141, 2012.

[55] Farzin Piltan, Sajad Rahmdel, Saleh Mehrara, Reza Bayat, "Sliding Mode Methodology Vs. Computed Torque Methodology Using MATLAB/SIMULINK and Their Integration into Graduate Nonlinear Control Courses" , International Journal of Engineering, 6(3): 142-177, 2012.

[56] Farzin Piltan, M.H. Yarmah moudi, M. Shamsodini, E.Mazlomian, A.Hosainpour. "PUMA-560 Robot Manipulator Position Computed Torque Control Methods Using MATLAB/SIMULINK and Their Integration into Graduate Nonlinear Control and MATLAB Courses", International Journal of Robotics and Automation, 3(3): 167-191, 2012.

[57] Farzin Piltan, Hossein Rezaie, Bamdad Boroomand, Arman Jahed. "Design Robust Backstepping on-line Tuning Feedback Linearization Control Applied to IC Engine", International Journal of Advance Science and Technology, 11:40-22, 2012.

[58] Farzin Piltan, S. Siamak, M.A. Bairami and I. Nazari. " Gradient Descent Optimal Chattering Free Sliding Mode Fuzzy Control Design: Lyapunov Approach", International Journal of Advanced Science and Technology, 43: 73-90, 2012.

[59] Farzin Piltan, M.R. Rashidian, M. Shamsodini and S. Allahdadi." Effect of Rule Base on the FuzzyBased Tuning Fuzzy Sliding Mode Controller: Applied to $2^{\text {nd }}$ Order Nonlinear System", International Journal of Advanced Science and Technology, 46:39-70, 2012.

[60] Farzin Piltan, A. Jahed, H. Rezaie and B. Boroomand." Methodology of Robust Linear Online High Speed Tuning for Stable Sliding Mode Controller: Applied to Nonlinear System", International Journal of Control and Automation, 5(3): 217-236, 2012.

[61] Farzin Piltan, R. Bayat, S. Mehara and J. Meigolinedjad. "GDO Artificial IntelligenceBased Switching PID Baseline Feedback Linearization Method: Controlled PUMA Workspace", International Journal of Information Engineering and Electronic Business, 5: 17-26, 2012.
[62] Farzin Piltan, B. Boroomand, A. Jahed and H. Rezaie. "Performance-Based Adaptive Gradient Descent Optimal Coefficient Fuzzy Sliding Mode Methodology", International Journal of Intelligent Systems and Applications, 11: 40-52 2012.

[63] Farzin Piltan, S. Mehrara, R. Bayat and S. Rahmdel. " Design New Control Methodology of Industrial Robot Manipulator: Sliding Mode Baseline Methodology", International Journal of Hybrid Information Technology, 5(4):41-54, 2012.

[64] AH Aryanfar, MR Khammar, Farzin Piltan, "Design a robust self-tuning fuzzy sliding mode control for second order systems", International Journal of Engineering Science REsearch, 3(4): 711-717, 2012.

[65] Farzin Piltan, Shahnaz Tayebi Haghighi, "Design Gradient Descent Optimal Sliding Mode Control of Continuum Robots", International Journal of Robotics and Automation, 1(4): 175-189, 2012.

[66] Farzin Piltan, A. Nabaee, M.M. Ebrahimi, M. Bazregar, "Design Robust Fuzzy Sliding Mode Control Technique for Robot Manipulator Systems with Modeling Uncertainties", International Journal of Information Technology and Computer Science, 5(8), 2013.

[67] Farzin Piltan, M. Akbari, M. Piran , M. Bazregar. "Design Model Free Switching Gain Scheduling Baseline Controller with Application to Automotive Engine", International Journal of Information Technology and Computer Science, 01:65-73, 2013.

[68] Farzin Piltan, M. Piran , M. Bazregar, M. Akbari, "Design High Impact Fuzzy Baseline Variable Structure Methodology to Artificial Adjust Fuel Ratio", International Journal of Intelligent Systems and Applications, 02: 59-70, 2013.

[69] Farzin Piltan, M. Mansoorzadeh, M. Akbari, S. Zare, F. ShahryarZadeh "Management of Environmental Pollution by Intelligent Control of Fuel in an Internal Combustion Engine" Global Journal of Biodiversity Science And Management, 3(1), 2013.

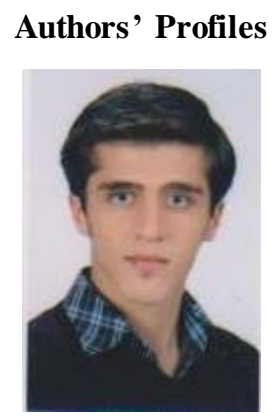

Iman Nazari is an electronic researcher in research and development company SSP. Co. His main areas of research interests are nonlinear control, artificial control systemand robotics. 


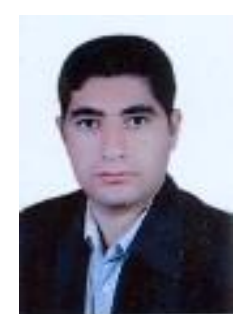

Ali Hosainpour is an electronic researcher of research and development company SSP. Co. His main areas of research interests are nonlinear control, artificial control systemand robotics.

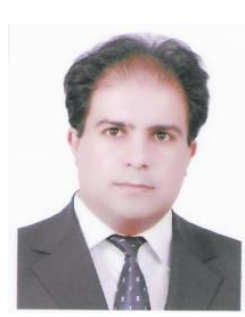

Farzin Piltan was born on 1975, Shiraz, Iran. In 2004 he is jointed the research and development company, SSP Co, Shiraz, Iran. In addition to 7 textbooks, Farzin Piltan is the main author of more than 80 scientific papers in refereed journals. $\mathrm{He}$ is editorial board of international journal of control and automation (IJCA), editorial board of International Journal of Intelligent System and Applications (IJISA), editorial board of IAES international journal of robotics and automation, editorial board of International Journal of Reconfigurable and Embedded Systems and reviewer of (CSC) international journal of robotics and automation. His main areas of research interests are nonlinear control, artificial control system and applied to FPGA, robotics and artificial nonlinear control and IC engine modelling and control.

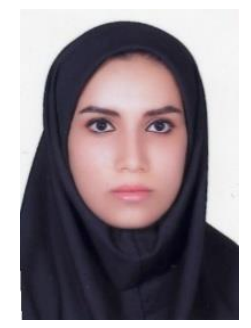

Sara Emamzadeh is a control and automation engineer researcher of research and development company SSP. Co. She is an expert artificial intelligence and control engineer in this company. Her research activities deal with the robotic control, artificial intelligence and expert system.

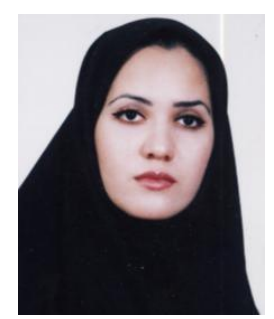

Mina Mirzaie is a computer researcher of research and development company SSP. Co. She is an expert artificial intelligence and computer engineer in this company. Her research activities deal with the robotic control, artificial intelligence and

How to cite this paper: Iman Nazari, Ali Hosainpour, Farzin Piltan, Sara Emamzadeh, Mina Mirzaie,"Design Sliding Mode Controller with Parallel Fuzzy Inference Sy stem Compensator to Control of Robot Manipulator", International Journal of Intelligent Systems and Applications(IJISA), vol.6, no.4, pp.63-75, 2014. DOI: 10.5815/ijisa.2014.04.07 